\title{
AUTOMATIC DESIGN MECHANISM FOR RESOURCE DISTRIBUTION FOR CONSTRUCTION OPERATIONS SIMULATION
}

\author{
T. M. Cheng ${ }^{1}$, M. Y. Hsu ${ }^{1}$, P. C. Chen ${ }^{1}$, C. C. $\operatorname{Lin}^{1}$ \\ ${ }^{1}$ Department of Construction Engineering, Chaoyang University of Technology, Wufong 413, \\ Taiwan \\ tmcheng@mail.cyut.edu.tw
}

\begin{abstract}
A planner may use simulation for in the analysis and design of construction operation processes to optimize overall performance of a construction system. Normally, the basic elements used in construction operation process simulation system such as CYCLONE (CYCLic Operation NEtworks) are activities and queues. Activity is used to model the execution of the task work which consumes resources and time to perform. Queue acts as a storage location for resources entering an idle state. In the simulation system, queues have to be created according to the ways of assigning resources to activities. Conventionally, planner creates queue at his/her judgment distinguishing what resources and how many should be allocated to which activity. This paper introduces a Genetic Algorithms (GA) based modeling mechanism for facilitating the automation of modeling resource distribution scenarios.
\end{abstract}

Keywords: GA, simulation, resource distribution.

\section{PROBLEM STATEMENT}

Computer simulation can be used in the analysis and design of construction operation processes. A planner may use simulation for resource distribution to optimize overall performance of a construction system. Normally, the basic elements used in construction operation process simulation system such as CYCLONE (CYCLic Operation NEtworks) are activities and queues. Activity is used to model the execution of the task work which consumes resources and time to perform. Queue acts as a storage location for resources entering an idle state. In the simulation system, queues have to be created according to the ways of assigning resources to activities. Conventionally, the resources assignment is modeled by planners. Planner creates queue at his/her judgment distinguishing what resources and how many should be allocated to which activity. For instance, suppose three activities (said 1,2, and 3) have to use resource A. There are five modeling ways to distribute A to those activities. All A can be modeled in one queue meaning the activities share the same pool of A. On the other hand, A may also be distributed to each activity without sharing, and then three queues have to be used in the model. Moreover, any two activities may share the same pool of A and one activity possesses its own A, and therefore two queues need to be drawn. One queue stores the resources shared by two activities and the other provides resource solitarily used by one activity. However, any two activities sharing the same pool of resource may generate different impact on the system performance, thus three different resource distribution scenarios have to be created (i.e., activity 1 and 2, 2 and 3, or 1 and 3 can be modeled for sharing the same pool of A) to see their impact. If the modeled system is complex, the possible resource distribution scenarios could be increased exponentially. This paper introduces a Genetic Algorithms (GA) based modeling mechanism for facilitating the automation of modeling resource distribution scenarios. CYCLONE modeling methodology will be used in the demonstration of this mechanism. In addition, related researches regarding GA-simulation, computer simulation system used for implementing the proposed mechanism, designed mechanism, and case verification are introduced in the following sections.

\section{BACKGROUND}

The following sections introduce the researches regarding the development of integrating simulation techniques with GA as well as essence of GA. In addition, the computer simulation system COST which was modified for the implementation of the designed mechanism is also presented.

\subsection{Related researches for integration of $G A$ and simulation techniques}

Due to improve the optimization capability, GA has been used in the integration of simulation technique in many areas for facilitating the optimal resource allocation planning. These researches include applying GA-simulation in the optimization of the pastoral dairy farm management [1], shipping and shipyard layout planning [2], the hard disk drive production scheduling [3], and ready-mixed-concrete trucks dispatching management [4]. Moreover, Cheng and Feng [5] integrated GA and simulation in 
the development of general purpose simulation system for use in the analysis of construction operations. Similarly, Hegazy and Kassab used GAsimulation technique for resource optimization in construction planning [6]. Though different types of applications of GA-simulation have been proposed, applying GA-simulation for automatically modeling resource distribution scenarios has not clearly pictured.

\subsection{CYCLONE methodology and COST program}

CYCLONE methodology developed by Halpin [7] is the first simulation system particularly designed for the planning and analysis of construction operation processes. Table 1 presents the basic modeling elements used in CYCLONE and reader may refer to [8] for the details. Since CYCLONE is widely used in the design and analysis for construction operations, several computer simulation systems or programs are developed based on it [5]. Among them, COST (Construction Operations Simulation Tool) was the newly developed one. In COST, the information required to build a CYCLONE model is input through dialogue boxes, as shown in Fig. 1. To explore the details of COST simulation package, readers may refer to Cheng's paper or the user manual of COST $[9,10]$.

Table 1 Modeling elements used in CYCLONE

\begin{tabular}{|c|c|l|}
\hline Name & Symbol & \multicolumn{1}{|c|}{ Function } \\
\hline $\begin{array}{c}\text { Normal } \\
\text { activity }\end{array}$ & & $\begin{array}{l}\text { Units arriving at Normal will be } \\
\text { processed right away without delaying. }\end{array}$ \\
\hline $\begin{array}{c}\text { Combination } \\
\text { (COMBI) } \\
\text { activity }\end{array}$ & & $\begin{array}{l}\text { Units arriving at COMBI will be } \\
\text { processed if units are available in all } \\
\text { preceding Queue node. }\end{array}$ \\
\hline $\begin{array}{l}\text { Queue node } \\
\text { Queue provides position that allows units } \\
\text { are delayed pending COMBI activities. }\end{array}$ \\
\hline $\begin{array}{c}\text { Consolidate } \\
\text { function } \\
\text { node }\end{array}$ & $\begin{array}{l}\text { Consolidate function node performs the } \\
\text { consolidate marking. }\end{array}$ \\
\hline Counter & $\begin{array}{l}\text { Counter measures the modeled system's } \\
\text { production rate. }\end{array}$ \\
\hline Arcs & $\begin{array}{l}\text { Arcs show the logic that units flow from } \\
\text { element to element. }\end{array}$ \\
\hline
\end{tabular}

\subsection{Genetic algorithms (GA)}

Genetic Algorithms (GA) is the search algorithm developed by Holland [11], which is based on the mechanics of natural selection and genetics to search through decision space for optimal solutions. The metaphor underlying GA is natural selection. In evolution, the problem that each species faces is to search for beneficial adaptations to the complicated and changing environment. In other words, each species has to change its chromosome combination to survive in the living world. In GA, a string represents a set of decisions (chromosome combination), a potential solution to a problem. Each string is evaluated on its performance with respect to the fitness function (objective function). The ones with better performance (fitness value) are more likely to survive than the ones with worse performance. Then the genetic information is exchanged between strings by crossover and perturbed by mutation. The result is a new generation with (usually) better survival abilities. This process is repeated until the strings in the new generation are identical, or certain termination conditions are met.

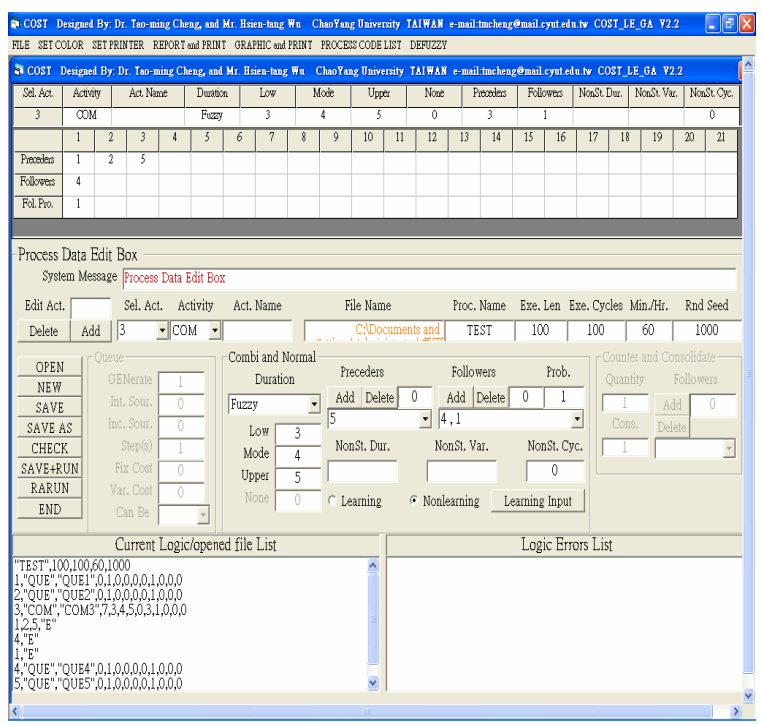

Fig. 1 The input interface of COST computer simulation system

\section{DESIGN MECHANISM}

The mechanism for automatic design of resource distribution in simulation system is described in two parts. One is the flows of how many queues are created and how resources are assigned in those queues and the other is how GA is integrated. The mechanism of how many queues is created and how resources are assigned in those queues is depicted in Fig. 2.

The integration of GA and the mechanism proposed in Fig. 2 is summarized as shown in Fig. 3. At first, a population of CYCLONE models is generated according to the mechanism depicted in Fig. 2. Secondly, numbers of strings $P(t)$ representing models created from first step are evaluated by simulating the CYCLONE models. These strings carry the genetic information of different resource distribution scenarios for the construction operation. Each string's fitness value is decided by simulating the CYCLONE models. The GA then uses the fitness value of each string to determine the probability that the string will be selected in the next generation, the better the fitness value the higher selection probability. GA operators, such as selection, crossover, and mutation, are then applied to the strings to produce the new offspring $C(t)$. The fitness 
value of the new offspring is again determined by simulating the CYCLONE models and the genetic operators are also applied to this new offspring. This process is repeated until the termination condition is reached.

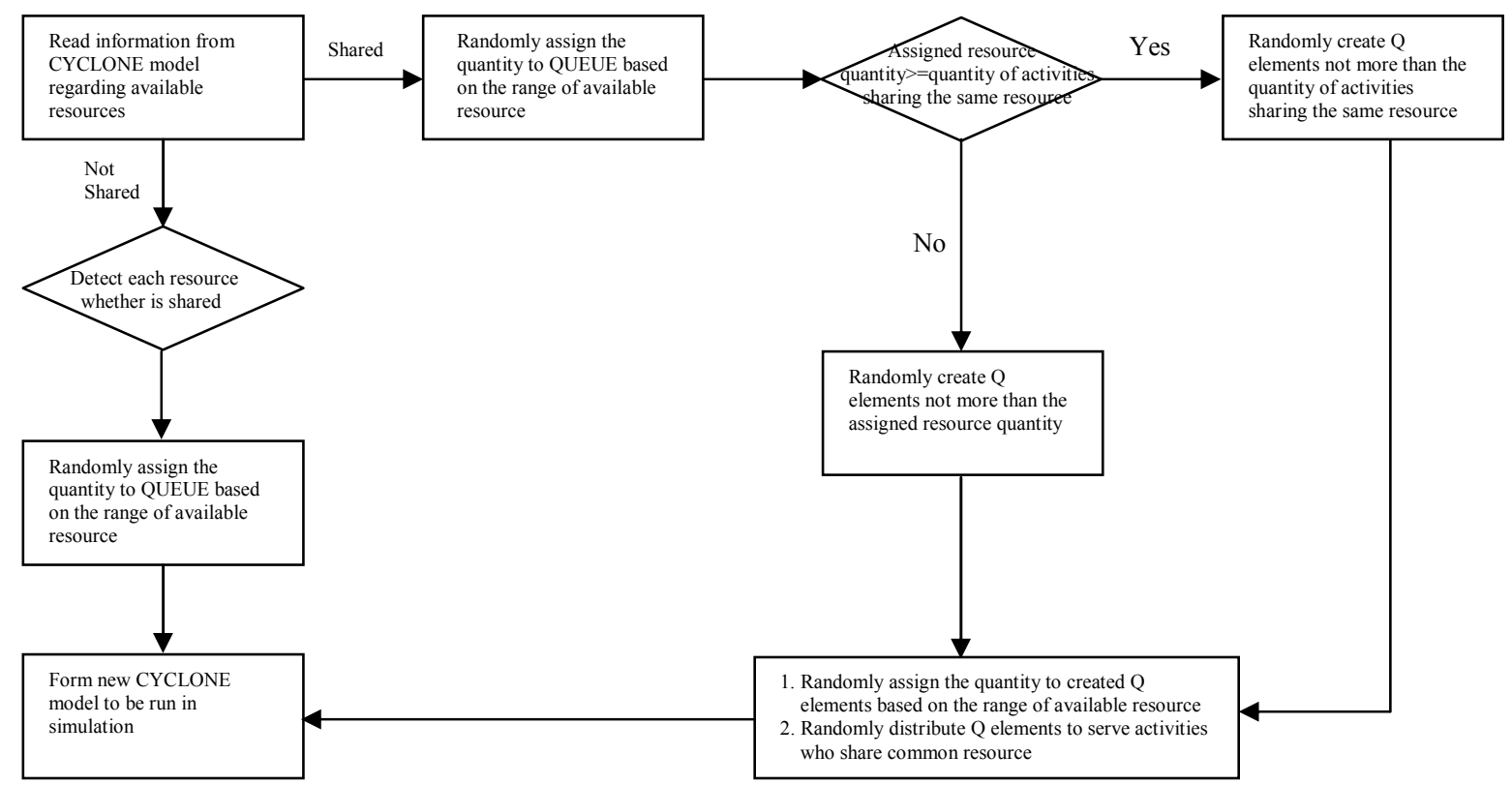

Fig. 2 Flows of forming resource distribution modeling scenarios

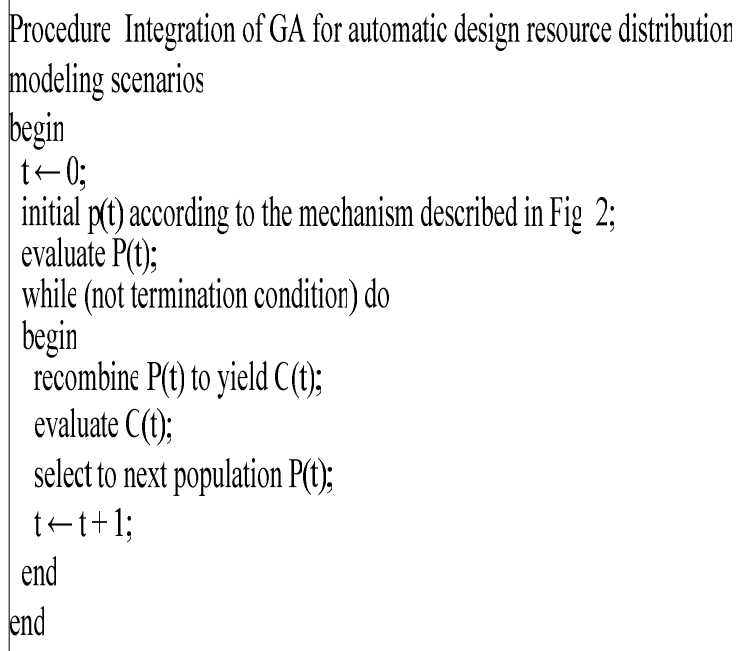

Fig. 3 A summary of integration GA and proposed mechanism

\section{CASE STUDY}

The tested CYCLONE model selected from Halpin and Riggs [8] describes the operation of producing the precast concrete elements and is shown in Fig. 4, namely type A model. In this model, concrete is first mixed in a batch plant and poured into precast forms. Then the concrete in the precast forms are steaming cured and moved to a curing tunnel. After being cured, the precast elements are finally transported to storage. In each production cycle, 10 elements will be generated. The resources defined in the model, their initial location, numbers of each resource, and the range of available resource units, together with cost information are given in Table 2. In order to eliminate the influence from uncertainty of activity duration, all activity durations are assumed fixed and given in Table 3.

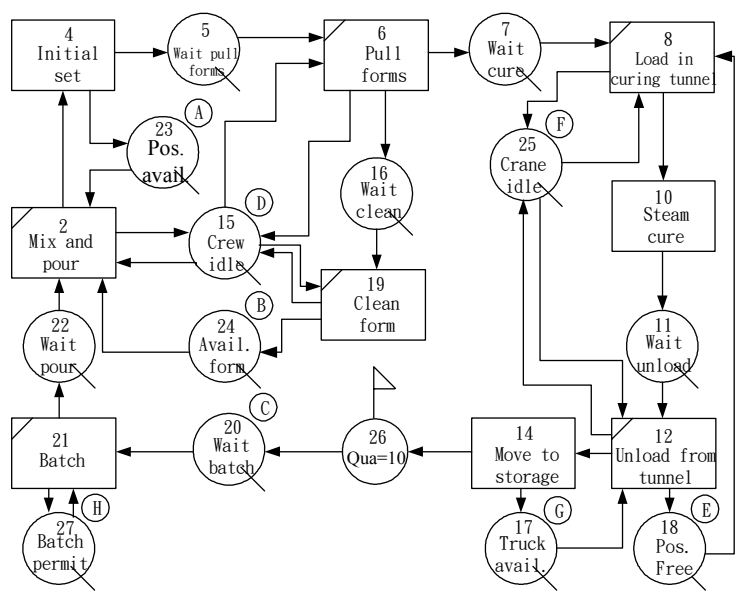

Fig. 4 Precast concrete element producing CYCLONE model (type A model)

As shown in Fig 4, there are two types of resource shared by more than one activity. One is "crew" as indicated by Queue 15 shared by activities 2, 6, and 19. The other is "crane" located in Queue 25 which is shared by activities 8 and 12. There are five and two modeling ways for redistributing resources crew and crane respectively, and together they can form 10 $\left(5^{*} 2\right)$ different CYCLONE modeling scenarios. For 
instance, Fig 5 demonstrates one of the 10 modeling scenarios (type B model). The "crew" resources are separated into two parts in the model. A new created Queue node numbered as 1 represents the crew used for activity 2 only and the other crews in Queue 15 are shared by activities 6 and 19. On the other hand, cranes in Queue 25 still remain being sharing by activities 8 and 12 .

Table 2 Available resources and cost information for tested model

\begin{tabular}{|c|c|c|c|c|c|}
\hline $\begin{array}{c}\text { Queue } \\
\text { node }\end{array}$ & $\begin{array}{c}\text { Resources } \\
\text { name }\end{array}$ & $\begin{array}{c}\text { Min. avail. } \\
\text { resources }\end{array}$ & $\begin{array}{c}\text { Max. avail. } \\
\text { resources }\end{array}$ & $\begin{array}{c}\text { Fixed } \\
\text { cost }(\$)\end{array}$ & $\begin{array}{c}\text { Variable } \\
\text { cost } \\
(\$ / \mathrm{hr})\end{array}$ \\
\hline 15 & Crew & 1 & 6 & 150 & 15 \\
\hline 17 & Truck & 2 & 6 & 170 & 17 \\
\hline 18 & Pos. & 3 & 12 & 180 & 18 \\
\hline 20 & Batch & 10 & 27 & 200 & 20 \\
\hline 23 & Pos. & 3 & 7 & 230 & 23 \\
\hline 24 & Form & 4 & 9 & 240 & 24 \\
\hline 25 & Crane & 1 & 3 & 250 & 25 \\
\hline 27 & $\begin{array}{c}\text { Batch } \\
\text { permit }\end{array}$ & 3 & 4 & 270 & 27 \\
\hline
\end{tabular}

Table 3 Duration of activities used in tested model

\begin{tabular}{|c|c|c|}
\hline $\begin{array}{c}\text { Element } \\
\text { number }\end{array}$ & Work tasks & $\begin{array}{c}\text { Activity duration } \\
\text { ( Minute) }\end{array}$ \\
\hline 2 & Mix and pour & 30 \\
\hline 4 & Initial set & 50 \\
\hline 6 & Pull forms & 20 \\
\hline 8 & $\begin{array}{c}\text { Load in curing } \\
\text { tunnel }\end{array}$ & 15 \\
\hline 10 & Steam cure & 120 \\
\hline 12 & $\begin{array}{c}\text { Unload from } \\
\text { tunnel }\end{array}$ \\
\hline 14 & Move to storage & 25 \\
\hline 19 & Clean form & 45 \\
\hline 21 & Batch & 18 \\
\hline
\end{tabular}

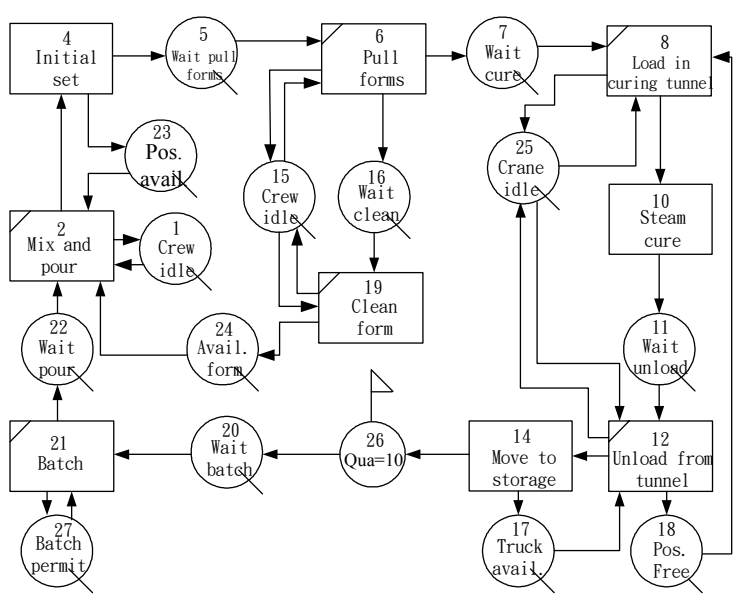

Fig. 5 Type B model for tested example

Table 4 lists all the 10 possible models as well as the ways of distributing the available resources given in Table 2 to those models. The 10 models describe the scenarios that how queues are arranged and what queues are assigned to what activities. In addition, there are 78 scenarios for distributing available resources to 10 models and together with $63,126,000$ resource combinations have to be searched for locating the best allocation scenario in order to maximize system performance such as lowering unit cost.

In order to compare the effectiveness of the proposed mechanism, estimating system performance has to be performed in advance. There are two system performance will be tested. One is maximizing system production rate and the other is minimizing system unit cost. As it can be estimated, there are around $6.3 * 10^{7}$ resources alternatives, which is not economical to go through the exhaustive enumeration of all resource combinations in terms of computation. As rule of thumb, the more resources are employed, the higher production rate is likely to be reached; therefore, a good guess of the best production rate could be obtained by using the maximum amount of resources for each work task. In addition, to estimate the possible range of production rate of the all resource combinations, the minimum amount of resources for each work task is also tested. The result shown in Table 5 that using type A model for testing indicates that the production rate of using the maximum amount of resources is 27.199 units per $\mathrm{hr}$, which is about 4.4 times of 6.201 cycles per hr by using the minimum amount of resources. In addition, the unit cost of using maximum amount of resources is $\$ 606$ per unit, which is about $60 \%$ of $\$ 1001$ per section by using the minimum amount of resources.

Table 4 Possible CYCLONE models, resource distribution scenarios, and resource combinations

\begin{tabular}{|c|c|c|c|c|c|c|c|}
\hline \multirow{3}{*}{$\begin{array}{l}\text { Type } \\
\text { of } \\
\text { model }\end{array}$} & \multirow{3}{*}{$\begin{array}{c}\text { Type of } \\
\text { resource } \\
\text { distribution } \\
\text { scenario }\end{array}$} & \multicolumn{5}{|c|}{ No. of queue node } & \multirow{3}{*}{$\begin{array}{c}\text { Possible } \\
\# \\
\text { of combin }\end{array}$} \\
\hline & & 15 & 1 & 3 & 25 & 9 & \\
\hline & & \multicolumn{5}{|c|}{ Range of available resource } & \\
\hline A & 1 & $1 \sim 6$ & N/A & $\mathrm{N} / \mathrm{A}$ & $1 \sim 3$ & $\mathrm{~N} / \mathrm{A}$ & 972,000 \\
\hline \multirow{5}{*}{ B } & 2 & 1 & $1 \sim 5$ & $\mathrm{~N} / \mathrm{A}$ & $1 \sim 3$ & $\mathrm{~N} / \mathrm{A}$ & 810,000 \\
\hline & 3 & $1 \sim 2$ & $1 \sim 4$ & $\mathrm{~N} / \mathrm{A}$ & $1 \sim 3$ & $\mathrm{~N} / \mathrm{A}$ & $1,296,000$ \\
\hline & 4 & $1 \sim 3$ & $1 \sim 3$ & $\mathrm{~N} / \mathrm{A}$ & $1 \sim 3$ & $\mathrm{~N} / \mathrm{A}$ & $1,458,000$ \\
\hline & 5 & $1 \sim 4$ & $1 \sim 2$ & $\mathrm{~N} / \mathrm{A}$ & $1 \sim 3$ & $\mathrm{~N} / \mathrm{A}$ & $1,296,000$ \\
\hline & 6 & $1 \sim 5$ & 1 & $\mathrm{~N} / \mathrm{A}$ & $1 \sim 3$ & $\mathrm{~N} / \mathrm{A}$ & 810,000 \\
\hline \multirow{5}{*}{$\mathrm{C}$} & 7 & 1 & $1 \sim 5$ & N/A & $1 \sim 3$ & N/A & 810,000 \\
\hline & 8 & $1 \sim 2$ & $1 \sim 4$ & $\mathrm{~N} / \mathrm{A}$ & $1 \sim 3$ & $\mathrm{~N} / \mathrm{A}$ & $1,296,000$ \\
\hline & 9 & $1 \sim 3$ & $1 \sim 3$ & $\mathrm{~N} / \mathrm{A}$ & $1 \sim 3$ & $\mathrm{~N} / \mathrm{A}$ & $1,458,000$ \\
\hline & 10 & $1 \sim 4$ & $1 \sim 2$ & $\mathrm{~N} / \mathrm{A}$ & $1 \sim 3$ & N/A & $1,296,000$ \\
\hline & 11 & $1 \sim 5$ & 1 & $\mathrm{~N} / \mathrm{A}$ & $1 \sim 3$ & N/A & 810,000 \\
\hline \multirow{5}{*}{ D } & 12 & 1 & $1 \sim 5$ & N/A & $1 \sim 3$ & $\mathrm{~N} / \mathrm{A}$ & 810,000 \\
\hline & 13 & $1 \sim 2$ & $1 \sim 4$ & N/A & $1 \sim 3$ & $\mathrm{~N} / \mathrm{A}$ & $1,296,000$ \\
\hline & 14 & $1 \sim 3$ & $1 \sim 3$ & $\mathrm{~N} / \mathrm{A}$ & $1 \sim 3$ & $\mathrm{~N} / \mathrm{A}$ & $1,458,000$ \\
\hline & 15 & $1 \sim 4$ & $1 \sim 2$ & $\mathrm{~N} / \mathrm{A}$ & $1 \sim 3$ & N/A & $1,296,000$ \\
\hline & 16 & $1 \sim 5$ & 1 & $\mathrm{~N} / \mathrm{A}$ & $1 \sim 3$ & N/A & 810,000 \\
\hline \multirow{8}{*}{$\mathrm{E}$} & 17 & 1 & 1 & $1 \sim 4$ & $1 \sim 3$ & N/A & 648,000 \\
\hline & 18 & 1 & $1 \sim 2$ & $1 \sim 3$ & $1 \sim 3$ & N/A & 972,000 \\
\hline & 19 & 1 & $1 \sim 3$ & $1 \sim 2$ & $1 \sim 3$ & N/A & 972,000 \\
\hline & 20 & 1 & $1 \sim 4$ & 1 & $1 \sim 3$ & N/A & 648,000 \\
\hline & 21 & $1 \sim 2$ & 1 & $1 \sim 3$ & $1 \sim 3$ & $\mathrm{~N} / \mathrm{A}$ & 972,000 \\
\hline & 22 & $1 \sim 2$ & $1 \sim 2$ & $1 \sim 2$ & $1 \sim 3$ & N/A & $1,296,000$ \\
\hline & 23 & $1 \sim 2$ & $1 \sim 3$ & 1 & $1 \sim 3$ & N/A & 972,000 \\
\hline & 24 & $1 \sim 3$ & 1 & $1 \sim 2$ & $1 \sim 3$ & N/A & 972,000 \\
\hline
\end{tabular}


Table 4 Possible resource distribution scenarios and resource combinations (continued)

\begin{tabular}{|c|c|c|c|c|c|c|c|}
\hline \multirow{3}{*}{$\begin{array}{l}\text { Type } \\
\text { of } \\
\text { model }\end{array}$} & \multirow{3}{*}{$\begin{array}{c}\text { Type of } \\
\text { resource } \\
\text { distribution } \\
\text { scenario }\end{array}$} & \multicolumn{5}{|c|}{ No. of queue node } & \multirow{3}{*}{$\begin{array}{c}\text { Possible } \\
\quad \# \\
\text { of combin. }\end{array}$} \\
\hline & & 15 & 1 & 3 & 25 & 9 & \\
\hline & & \multicolumn{5}{|c|}{ Range of available resource } & \\
\hline \multirow{2}{*}{$\mathrm{E}$} & 25 & $1 \sim 3$ & $1 \sim 2$ & 1 & $1 \sim 3$ & N/A & 972,000 \\
\hline & 26 & $1 \sim 4$ & 1 & 1 & $1 \sim 3$ & N/A & 648,000 \\
\hline \multirow{2}{*}{$\mathrm{F}$} & 27 & $1 \sim 6$ & N/A & $\mathrm{N} / \mathrm{A}$ & 1 & $1 \sim 2$ & 648,000 \\
\hline & 28 & $1 \sim 6$ & N/A & $\mathrm{N} / \mathrm{A}$ & $1 \sim 2$ & 1 & 648,000 \\
\hline \multirow{10}{*}{ G } & 29 & 1 & $1 \sim 5$ & N/A & 1 & $1 \sim 2$ & 540,000 \\
\hline & 30 & 1 & $1 \sim 5$ & N/A & $1 \sim 2$ & 1 & 540,000 \\
\hline & 31 & $1 \sim 2$ & $1 \sim 4$ & N/A & 1 & $1 \sim 2$ & 864,000 \\
\hline & 32 & $1 \sim 2$ & $1 \sim 4$ & N/A & $1 \sim 2$ & 1 & 864,000 \\
\hline & 33 & $1 \sim 3$ & $1 \sim 3$ & $\mathrm{~N} / \mathrm{A}$ & 1 & $1 \sim 2$ & 972,000 \\
\hline & 34 & $1 \sim 3$ & $1 \sim 3$ & N/A & $1 \sim 2$ & 1 & 972,000 \\
\hline & 35 & $1 \sim 4$ & $1 \sim 2$ & N/A & 1 & $1 \sim 2$ & 864,000 \\
\hline & 36 & $1 \sim 4$ & $1 \sim 2$ & $\mathrm{~N} / \mathrm{A}$ & $1 \sim 2$ & 1 & 864,000 \\
\hline & 37 & $1 \sim 5$ & 1 & $\mathrm{~N} / \mathrm{A}$ & 1 & $1 \sim 2$ & 540,000 \\
\hline & 38 & $1 \sim 5$ & 1 & N/A & $1 \sim 2$ & 1 & 540,000 \\
\hline \multirow{10}{*}{$\mathrm{H}$} & 39 & 1 & $1 \sim 5$ & N/A & 1 & $1 \sim 2$ & 540,000 \\
\hline & 40 & 1 & $1 \sim 5$ & N/A & $1 \sim 2$ & 1 & 540,000 \\
\hline & 41 & $1 \sim 2$ & $1 \sim 4$ & N/A & 1 & $1 \sim 2$ & 864,000 \\
\hline & 42 & $1 \sim 2$ & $1 \sim 4$ & N/A & $1 \sim 2$ & 1 & 864,000 \\
\hline & 43 & $1 \sim 3$ & $1 \sim 3$ & N/A & 1 & $1 \sim 2$ & 972,000 \\
\hline & 44 & $1 \sim 3$ & $1 \sim 3$ & N/A & $1 \sim 2$ & 1 & 972,000 \\
\hline & 45 & $1 \sim 4$ & $1 \sim 2$ & N/A & 1 & $1 \sim 2$ & 864,000 \\
\hline & 46 & $1 \sim 4$ & $1 \sim 2$ & N/A & $1 \sim 2$ & 1 & 864,000 \\
\hline & 47 & $1 \sim 5$ & 1 & N/A & 1 & $1 \sim 2$ & 540,000 \\
\hline & 48 & $1 \sim 5$ & 1 & N/A & $1 \sim 2$ & 1 & 540,000 \\
\hline \multirow{10}{*}{ I } & 49 & 1 & $1 \sim 5$ & N/A & 1 & $1 \sim 2$ & 540,000 \\
\hline & 50 & 1 & $1 \sim 5$ & N/A & $1 \sim 2$ & 1 & 540,000 \\
\hline & 51 & $1 \sim 2$ & $1 \sim 4$ & N/A & 1 & $1 \sim 2$ & 864,000 \\
\hline & 52 & $1 \sim 2$ & $1 \sim 4$ & N/A & $1 \sim 2$ & 1 & 864,000 \\
\hline & 53 & $1 \sim 3$ & $1 \sim 3$ & N/A & 1 & $1 \sim 2$ & 972,000 \\
\hline & 54 & $1 \sim 3$ & $1 \sim 3$ & N/A & $1 \sim 2$ & 1 & 972,000 \\
\hline & 55 & $1 \sim 4$ & $1 \sim 2$ & N/A & 1 & $1 \sim 2$ & 864,000 \\
\hline & 56 & $1 \sim 4$ & $1 \sim 2$ & N/A & $1 \sim 2$ & 1 & 864,000 \\
\hline & 57 & $1 \sim 5$ & 1 & N/A & 1 & $1 \sim 2$ & 540,000 \\
\hline & 58 & $1 \sim 5$ & 1 & N/A & $1 \sim 2$ & 1 & 540,000 \\
\hline \multirow{20}{*}{$\mathrm{J}$} & 59 & 1 & 1 & $1 \sim 4$ & 1 & $1 \sim 2$ & 432,000 \\
\hline & 60 & 1 & 1 & $1 \sim 4$ & $1 \sim 2$ & 1 & 432,000 \\
\hline & 61 & 1 & $1 \sim 2$ & $1 \sim 3$ & 1 & $1 \sim 2$ & 648,000 \\
\hline & 62 & 1 & $1 \sim 2$ & $1 \sim 3$ & $1 \sim 2$ & 1 & 648,000 \\
\hline & 63 & 1 & $1 \sim 3$ & $1 \sim 2$ & 1 & $1 \sim 2$ & 648,000 \\
\hline & 64 & 1 & $1 \sim 3$ & $1 \sim 2$ & $1 \sim 2$ & 1 & 648,000 \\
\hline & 65 & 1 & $1 \sim 4$ & 1 & 1 & $1 \sim 2$ & 432,000 \\
\hline & 66 & 1 & $1 \sim 4$ & 1 & $1 \sim 2$ & 1 & 432,000 \\
\hline & 67 & $1 \sim 2$ & 1 & $1 \sim 3$ & 1 & $1 \sim 2$ & 648,000 \\
\hline & 68 & $1 \sim 2$ & 1 & $1 \sim 3$ & $1 \sim 2$ & 1 & 648,000 \\
\hline & 69 & $1 \sim 2$ & $1 \sim 2$ & $1 \sim 2$ & 1 & $1 \sim 2$ & 864,000 \\
\hline & 70 & $1 \sim 2$ & $1 \sim 2$ & $1 \sim 2$ & $1 \sim 2$ & 1 & 864,000 \\
\hline & 71 & $1 \sim 2$ & $1 \sim 3$ & 1 & 1 & $1 \sim 2$ & 648,000 \\
\hline & 72 & $1 \sim 2$ & $1 \sim 3$ & 1 & $1 \sim 2$ & 1 & 648,000 \\
\hline & 73 & $1 \sim 3$ & 1 & $1 \sim 2$ & 1 & $1 \sim 2$ & 648,000 \\
\hline & 74 & $1 \sim 3$ & 1 & $1 \sim 2$ & $1 \sim 2$ & 1 & 648,000 \\
\hline & 75 & $1 \sim 3$ & $1 \sim 2$ & 1 & 1 & $1 \sim 2$ & 648,000 \\
\hline & 76 & $1 \sim 3$ & $1 \sim 2$ & 1 & $1 \sim 2$ & 1 & 648,000 \\
\hline & 77 & $1 \sim 4$ & 1 & 1 & 1 & $1 \sim 2$ & 432,000 \\
\hline & 78 & $1 \sim 4$ & 1 & 1 & $1 \sim 2$ & 1 & 432,000 \\
\hline & & & & & & total & $63,126,000$ \\
\hline
\end{tabular}

Table 5. Best guess of both the production rate and unit cost of the tested example

\begin{tabular}{|c|c|c|}
\hline Item & $\begin{array}{c}\text { Guess of } \\
\text { possible worse } \\
\text { result }\end{array}$ & $\begin{array}{c}\text { Guess of } \\
\text { possible best } \\
\text { result }\end{array}$ \\
\hline $\begin{array}{c}\text { System } \\
\text { production rate }\end{array}$ & $\begin{array}{c}6.201 \\
\text { (units/hr) }\end{array}$ & $\begin{array}{c}27.199 \\
\text { (units/hr) }\end{array}$ \\
\hline System unit cost & \$1001/unit & $\$ 606 /$ unit \\
\hline & Q15(1), Q17(2), & Q15(6), Q17(6), \\
Resource & Q18(3), & Q18(12), \\
combination & Q20(10), & Q20(27), \\
& Q23(3), Q24(4), & Q23(7), Q24(9), \\
& Q25(1), Q27(3) & Q25(3), Q27(4) \\
\hline
\end{tabular}

Higher production rate could be reached by using maximum amount of resource combination; however, it is not clear whether the production rate of the best guess is the highest. Therefore, the example is tested by using the proposed mechanism. However, users only need to choose one of the 10 models as the input model for running simulation. In other word, user does not to input 10 models manually as conventional way.

The input parameters for running GA such as population size, generation number, crossover rate and mutation rate are set to $40,30,0.5$, and 0.05 respectively according to Cheng's and Feng's suggestion [5]. As a result, the best system production rate and unit cost obtained by running new mechanism are 27.574 cycles per hr and $\$ 435$ per unit for system production rate and unit cost, respectively (final results shown in Table 6). Compared to the best guess of the production rate, the solution obtained by running the designed mechanism is clearly better. In addition, only 1200 (= $40 * 30)$ resource combinations are explored. In other word, only $0.0019 \%(=1,200 / 63,126,000)$ of possible solution space is explored, and then a better solution with little computation effort is presented. Moreover, the mechanism is implemented via reprogramming COST simulation system and the interface is shown in Fig. 7.

Table 6 Case study testing results

\begin{tabular}{|c|c|c|}
\hline Item & $\begin{array}{c}\text { Best system } \\
\text { production rate }\end{array}$ & $\begin{array}{c}\text { Best system } \\
\text { unit cost }\end{array}$ \\
\hline $\begin{array}{c}\text { System production } \\
\text { rate }\end{array}$ & $27.574($ units/hr) & \$435/unit \\
\hline $\begin{array}{c}\text { Resource } \\
\text { combination }\end{array}$ & Q15(2), Q1(4), & Q15(1), Q1(1), \\
& Q17(6), & Q3(2), Q17(2), \\
& Q18(12), & Q18(5), \\
& Q23(5), Q24(9), & Q20(10), \\
& Q25(3), Q27(4), Q24(5), & Q25(1), Q27(3) \\
\hline Model Type & Type B as & Type E as \\
& shown in Fig 5 & shown in Fig 6 \\
\hline
\end{tabular}




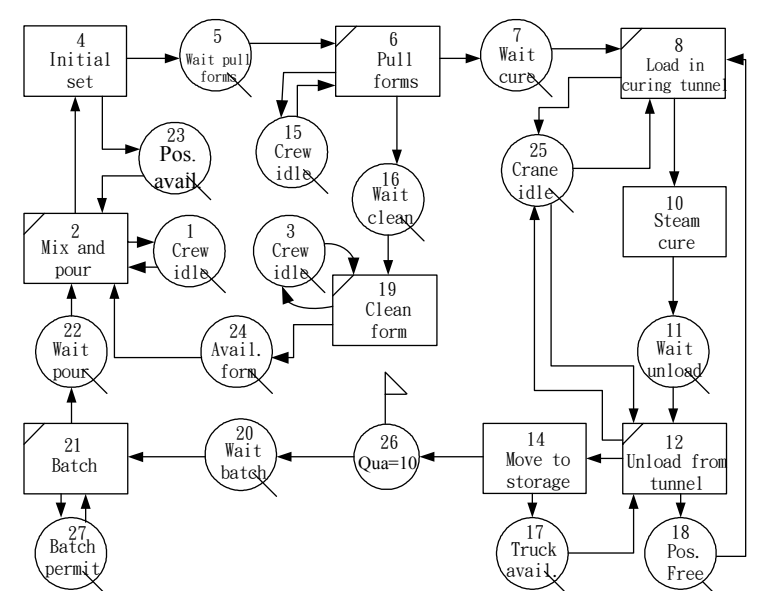

Fig. 6 Type E CYCLONE model for tested example

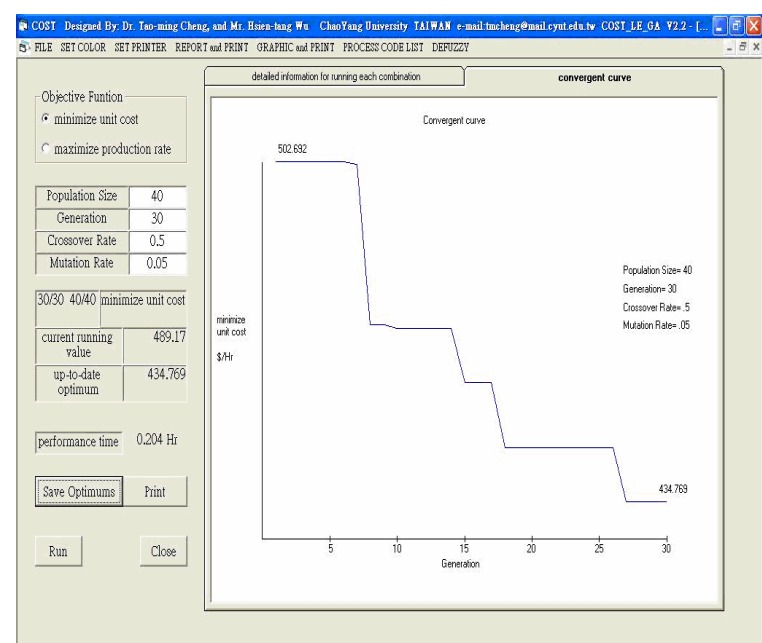

Fig. 7 An interface showing convergent curve while running simulation

\section{CONCLUSIONS}

Simulation technique is easily used for modeling resource distribution scenarios for construction operations. Conventionally, planner has to create queue elements for storing resources used for activities. If more than one resource distribution modeling ways, user has to input models as many as possible resource distribution scenarios. Moreover, if there are many resource alternatives, it becomes uneconomically for running each resource combination in all models. This research proposes a mechanism that applying GA for facilitating the resource distribution scenario modeling task. The mechanism allows planners input any resource distribution modeling scenario and automatically search the optimal ways for resource allocation. In other word, planners only need to focus on what resource has to be used in what activity rather than worry about drawing possible models describing different resource distribution scenarios. From the case study, the proposed mechanism shows that with little computation and modeling efforts, a better result is obtained for improving system performance.

\section{Acknowledgments}

This work was supported in part by the National Science Council, Taiwan under Grant No. NSC922211-E-324-023.

\section{REFERENCES}

[1] Parmar, R. S., McClendon, R. W., and Potter W. D., "Farm machinery selection using simulation and genetic algorithms", Transactions of the ASAE, Vol. 39, No. 5, pp. 1905-1909, 1996.

[2] Bruzzone, A., and Signorile, R., "Simulation and genetic algorithms for ship planning and shipyard layout”, Simulation, Vol. 71, No. 2, pp. 74-83, 1998.

[3] Zhao, Z. Y., and Souza R. de, "Genetic production line-balancing for the hard disk drive industry", The International Journal of Advanced Manufacturing Technology, Vol. 16, pp. 297-302, 2000.

[4] Feng, C.-W., Cheng, T.-M., and Wu, H.-T., "Optimizing the schedule of dispatching RMC trucks through genetic algorithms", Automation in Construction, Vol. 13, pp. 327-340, 2004.

[5] Cheng, T.-M. and Feng, C.-W., "An effective simulation mechanism for construction operations", Automation in Construction, Vol. 12, pp. 227-244, 2003.

[6] Hegazy, T. and Kassab, M., "Resource optimization using combined simulation and genetic algorithms", Journal of Construction Engineering and Management, ASCE, Vol. 129, No. 6, pp. 698$705,2003$.

[7] Halpin, D. W., "CYCLONE - method for modeling job site processes", Journal of Construction Division, ASCE, Vol. CO3, pp. 489499, 1977.

[8] Halpin, D. W., and Riggs, L. S., Planning and analysis of construction operations, Wiley, New York, 1992.

[9] Cheng, T.-M., Wu, S.-T., and Tseng, Y.-W., "Construction operation simulation tool - COST", Proceedings of Symposium of 17th ISARC, April, Taipei, pp. 1143-1146, 2000.

[10] Cheng, T.-M., and Wu, S.-T., COST user manual, Department of Construction Engineering, Chaoyang University of Technology, Taiwan, 2001.

[11] Goldberg, D. E., Genetic algorithms in search, optimization, and machine learning, Addison-Wesley, New York, 1989. 